\title{
Genital Self-Mutilation: A Case Report
}

\author{
Genital Self Mutilasyon; Olgu Sunumu
}

\author{
Hülya Yılmaz Başer ${ }^{1}$, Aykut Başer ${ }^{2}$, Atakan Yılmaz' , Emrah Uyanık¹, Mustafa Serinken \\ 'Department of Emergency Medicine, Pamukkale University Faculty of Medicine, Denizli, Turkey \\ 2Department of Urology, Pamukkale University Faculty of Medicine, Denizli, Turkey
}

\begin{abstract}
Introduction: A marked increase in emergency department (ED) patients showing the application of behavior disorders has been observed in recent years. In the last two decades, mental healthrelated visits to U.S. EDs increased from 17.1 to 23.6 per 1000 U.S. population. The first applications were reported in $6.3 \%$ of the population. Emergency contact with genital self-mutilation is very rare. Knowingly and willfully requests without the individual's death is known as damaging his own self-mutilation. Klingsor Syndrome, also known as genital self-mutilation, is often associated with psychosis.
\end{abstract}

Case Report: A 46-year-old male patient was admitted to ED complaining of scrotal pain and bleeding. On assessment of the patient's genitals, self-mutilation was diagnosed.

Conclusion: Our aim is to provide treatment to these ED patients presenting with genital trauma and genital injury with psychosis; furthermore, genital self-mutilation can be a severe psychiatric symptom and should not be ignored. As in many diseases, a detailed history and physical examination should be allocated enough time in these cases.

Keywords: Genital self-mutilation, Klingsor Syndrome, genital trauma, emergency department

Received: 22.02.2015 Accepted:03.04.2015

Available Online Date: 12.05.2015

\section{ÖZET}

Giriş: Son yıllarda davranış bozukluğu gösteren hastaların acil servise başvurularında anlamlı bir artış gözlenmektedir. Son 20 yıl için Amerika Birleşik Devletlerinde bu oran 1000'de 17,1'den 23,6'ya ulaşmıştır. Illk başvurular içinde \%6,3 olarak bildirilmiştir. Genital self mutilasyon ile acile başvuru ise çok nadir görülmektedir. Self mutilasyon; ölüm isteği olmaksızın bireyin bilerek ve isteyerek, kendi bedeninin bir bölgesine zarar vermesi olarak tanımlanır. Klingsor Sendromu olarak da bilinen genital self mutilasyon genellikle psikoz ile ilişkilidir.

Olgu Sunumu: Kırk altı yaşında erkek hasta, acil servise skrotal ağı ve kanama şikâyeti ile başvurdu. Hastanın yapılan değerlendirmesinde genital self mutilasyon tanısı konuldu.

Sonuç: Acil servise genital travma ile başvuran bu olguyu sunmadaki amacımız, genital yaralanma ile başvuran olgularda da, genital self mutilasyon olabileceği düşünülerek psikoz gibi ağır psikiyatrik yakınmalar göz ardı edilmemeli. Birçok hastalıkta olduğu gibi bu olgularda da ayrıntılı öykü ve fizik muayene için yeterli zaman ayrılmalıdır.

Anahtar Kelimeler: Genital self mutilasyon, Klingsor Sendromu, genital travma, acil servis

Geliş Tarihi: 22.02.2015 Kabul Tarihi: 03.04.2015

Çevrimiçi Yayın Tarihi: 12.05 .2015

\section{Giriş}

Self mutilasyon, ölüm isteği olmaksızın bireyin bilerek ve isteyerek, kendi bedeninin bir bölgesine zarar vermesi olarak tanımlanır. Kendine zarar vermenin en yaygın türleri cilde, gözlere ya da genital bölgeye zarar vermedir (1). Ülkemizde genital self mutilasyon (GSM) ile acil servise başvuru durumlarına nadir rastlanılır. Genital self-mutilasyon en sık 20-29 yaş aralığında ve erkeklerde kadınlara göre daha sık görülmektedir $(2,3)$. Ülkemizde erkek GSM'nun gerçek prevalansı vakaların çoğu rapor edilmediğinden bilinmemektedir (4). Bu yazıda acil servise başvuran bir erkek GSM olgusu sunulmuş ve konu güncel literatür bilgileri ışı̆̆ında tartışılmıştır.

\section{Olgu Sunumu}

Kırk altı yaşında erkek hasta, acil servise skrotal ağrı ve kanama şikâyeti ile başvurdu. Hastanın genel durumu iyi ve vital bulguları olağandı. Fizik bakısında sol hemiskrotumda yaklaşık 4 cmlik cilt, cilt altı bir kesi saptandı ve sol testis palpe edilemedi (Resim 1). 


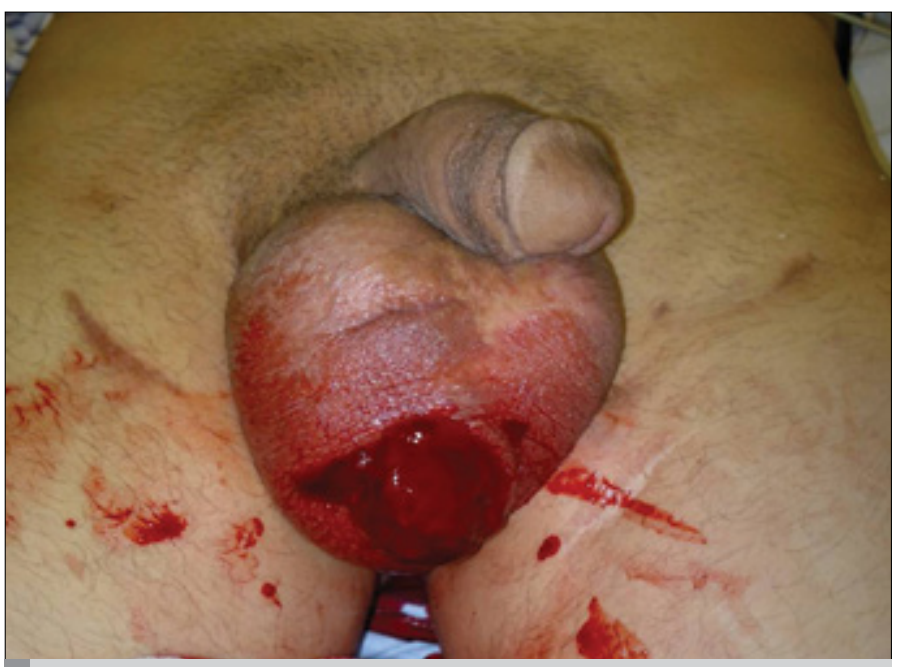

Resim 1. Hastanın sol hemiskrotumdaki kesisi

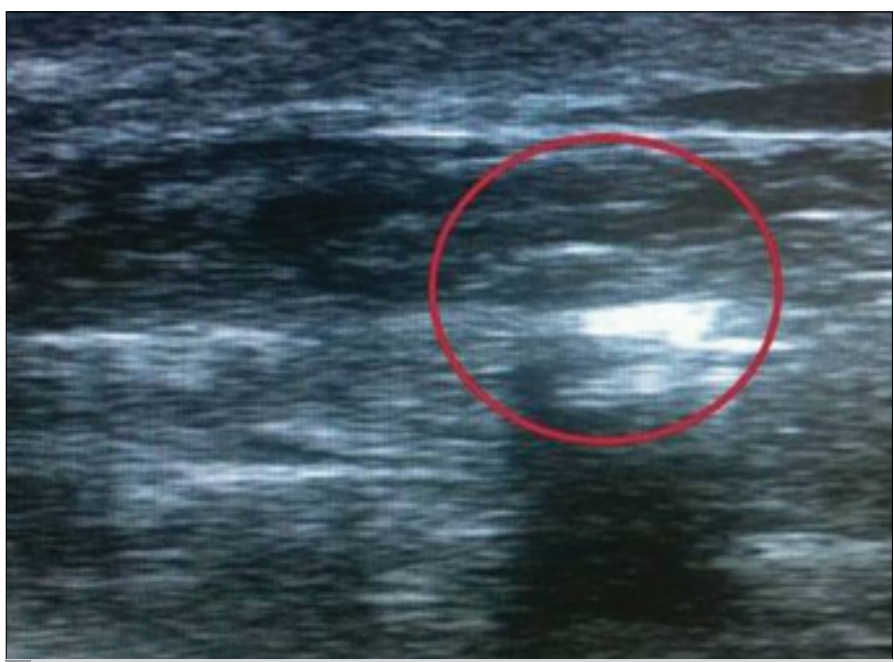

Resim 2. Sol hemiskrotum USG görüntülenmesinde heterojenite ve nodüler görünüm ile birlikte testiküler dokunun seçilememesi

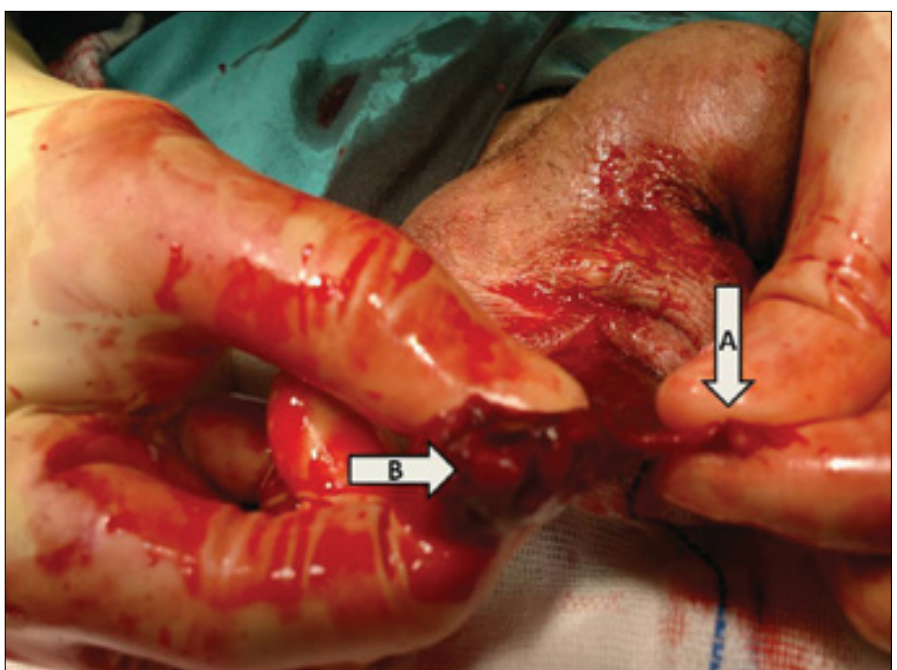

Resim 3. Operasyon sırasında sol vaz deferens (Ok $A$ ) ve spermatik kordda (Ok B) saptanan kesiler
Hastanın anamnezinde; 4 yı önce eşinden boşandığı, 1 kızı olduğu ve 3 yıldır işsiz olduğu öğrenildi. Özgeçmiş sorgulamasında ise kronik hastalık saptanmadı. Hastanın tanı almış bir psikiyatrik hastalığı ve düzenli ilaç kullanım öyküsü yoktu. Hastaya travmanın nasıl oluştuğuna dair sorgulama yapıldığında; komşusuna bir meseleden dolayı sinirlendiğini ve sinirli haldeyken testisini kestiği öğrenildi.

Yapılan ultrasonografide; sağ testis 20x32x 43 mm boyutlarda ölçülmüş olup parankim olağandı. Sol testis sınırları net seçilememekle birlikte belirgin heterojen ve nodularite gösteren alanlar izlendi (Resim 2). Hastanın doppler ultrasonunda sol testise ait kanlanma saptanmadı. Hasta üroloji tarafından acil skrotal ekplorasyona alındı. Operasyon sırasında sol testis izlenmedi, sol vaz deferensin ve spermatik kordun kesik olduğu görüldü (Resim 3). Hasta operasyon sonrası üroloji servisinde takip edildi taburculuk sonrasında psikiyatri bölümüne devredildi.

Hastanın acil serviste ve psikiyatri servisindeki psikiyatrik değerlendirilmelerinde; Depresif/anksiyöz olduğu ve zaman zaman işitsel halüsinasyonlardan şikâyet ettiği öğrenildi. Aktif psikotik içerik alınamadı. Aktif pasif suisidal düşüncesi yoktu. 2 yıl önce de benzer bir girişimi olduğu öğrenildi. Onu niçin yaptığını da hatırlamıyordu. Bunlardan başka kendine zarar verme girişimi tariflemiyordu. Hasta yaptığı bu eylemlerden çok pişmanlık duyuyordu. Hasta medikal tedavi sonrası bir hafta sonra taburcu edildi.

\section{Tartışma}

Self mutilasyon ile ilgili yazılar eski çağlara kadar uzanmaktadır. Eski yunan mitolojisinde Tanrı Eshmun, Tanrıça Astronae'ya karşı erotik gelişmelerden kaçınmak için kendini hadım etmiş; bu nedenle kendi kendini hadım etme, Eshmun Kompleksi olarak da bilinir (5). Farklı kültürlerde benzer hikayeler bulunmakla birlikte tıbbi literatürde ilk olarak 1946'da suçluluk duyguları içinde her iki göz nüvesini çıkarmış olan kadın hastadan bahsedilmektedir (6).

Genital self mutilasyon nadir görülen bir durumdur. Aboseif ve ark. (7) 19 genital self mutilasyonlu 14 hastada yaptıkları inceleme sonucunda bu hastaların \%65'inin psikotik, \%35'inin psikotik olmadığını saptamışlardır. Bu yaralanmaların, penis ve skrotal cilt laserasyonlarından total amputasyonlara kadar değiştiğini fakat psikotik olan ve olmayan hastalar arasında yaralanma şiddetinin farklı olmadığını belirtmişlerdir. Aboseif ve ark. (7) genital self mutilasyon tekrarını \%31 olarak belirtirken, Ristic ve ark. (8) vakaların çoğunun tek bir epizod ile geldiğini belirtmişlerdir. Bu yazıda sunulan olgunun öyküsünde iki yı önce de benzer bir self mutilasyon girişimi bulunmaktadır. Sonuç olarak self mutilasyon girişimlerinin tekrar etme riski olduğu unutulmamalı ve hastaya gerekli psikiyatrik desteğin verilmesi sağlanmalıdır.

Erkekte genital self-mutilasyon olgularının çoğunda psikotik bir hastalık bildirilmiştir. Çalışmalarda self-mutilasyon gözlenen hastalarda; şizofreni \%51, affektif psikoz \%15 ve organik/toksik psikoz \%17 oranında rastlanmaktadır (9). Son yıllarda davranış bozukluğu gösteren hastaların acil servise başvurularında anlamlı bir artış gözlenmektedir. Son 20 yıl için Amerika Birleşik Devletlerinde 
bu oran 1000'de 17,1'den 23,6'ya ulaşmıştır. İlk başvurular içinde oran $\% 6,3$ olarak bildirilmiştir (10).

\section{Sonuç}

Sonuç olarak, genital self mutilasyon olguları daha çok ağır psikiyatrik rahatsızlığı olan olgularda görülmektedir ve bu olgulara yaklaşımda ilgili cerrahi branşın yanında mutlaka psikiyatrinin de işbirliği gerekir. Bir başka önemli nokta da, acil servise başvuran travma hastalarında psikiyatrik yakınması olsun veya olmasın self mutilasyon olabileceğini düşünerek ayrıntılı öykü ve fizik muayene için yeterli zaman ayrılmalıdır.

Informed Consent: Written informed consent was obtained from the patient who participated in this case.

Peer-review: Externally peer-reviewed.

Author Contributions: Concept - H.Y.B., M.S.; Design - A.B., A.Y.; Supervision H.Y.B., M.S.; Materials - E.U., A.B; Data Collection and/or Processing - A.Y., E.U.; Analysis and/or Interpretation - A.B., M.S.; Literature Review - H.Y.B.; Writer H.Y.B., M.S.; Critical Review - M.S.

Conflict of Interest: No conflict of interest was declared by the authors.

Financial Disclosure: The authors declared that this study has received no financial support.

Hasta Onamı: Yazılı hasta onamı bu olguya katılan hastadan alınmıştır.

Hakem değerlendirmesi: Dış bağımsız.
Yazar Katkıları: Fikir - H.Y.B., M.S.; Tasarım - A.B., A.Y.; Denetleme - H.Y.B., M.S.; Malzemeler - E.U., A.B.; Veri toplanması ve/veya işlemesi - A.Y., E.U.; Analiz ve/ veya yorum - A.B., M.S.; Literatür taraması - H.Y.B.; Yazıyı yazan - H.Y.B., M.S.; Eleştirel İnceleme - M.S.

Çıkar Çatışması: Yazarlar çıkar çatışması bildirmemişlerdir.

Finansal Destek: Yazarlar bu çalışma için finansal destek almadıklarını beyan etmişlerdir.

\section{Kaynaklar}

1. Feldman MD. The challenge of self-mutilation: a review. Compr Psychiatry 1988; 29: 252-69. [CrossRef]

2. Schweitzer I. Genital self amputation and the Klingsor syndrome. Aust N Z J Psychiatry 1990; 24: 566-9. [CrossRef]

3. Greilsheimer H, Groves JE. Male genital self-mutilation. Arch Gen Psychiatry 1979; 36: 441-6. [CrossRef]

4. Bilge Burçak Annagür, Lut Tamam. Erkek Genital Self-Mutilasyon: Bir Psikotik Bozukluk Olgusu. Selçuk Üniv Tıp Derg 2011; 27: 240-1.

5. Kushner AW. Two cases of auto-castration due to religious delusions. $\mathrm{Br}$ J Med Psychol 1967; 40: 293-8. [CrossRef]

6. Favazza AR, Conterio K. Female habitual self- mutilators. Acta Psychiatr Scand 1989; 79: 283-9. [CrossRef]

7. Aboseif S, Gomez R, McAninch JW. Genital self mutilation. J Urol 1993; 150: 1143

8. Ristić DI, Petrović D, Cirić Z. Penile self-mutilation-two cases in one family. Psychiatr Danub 2008; 20: 332-6.

9. Martin T, Gattaz WF. Psychiatric aspects of male genital self-mutilation. Psychopathology 1991; 24: 170-8. [CrossRef]

10. Larkin GL, Beautrais AL. Chapter 283. Behavioral Disorders: Emergency Assessment. In: Tintinalli JE, Stapczynski JS, Cline DM, Ma OJ, Cydulka RK, Meckler GD, eds. Tintinalli's Emergency Medicine: A Comprehensive Study Guide. $7^{\text {th }}$ ed: http://www.accessmedicine.com. Access date Feb 6, 2015. 